\title{
Effect of Triclosan Toothpaste on Gingivitis and Plaque Accumulation in Children Wearing Fixed Orthodontic Appliances: A Randomized Clinical Trial

\author{
Bayoumi $\mathrm{M}^{1} B D S$, Hanno A $\mathrm{A}^{2} P h D$, Sharaf A $\mathrm{A}^{2} P h D$.
}

\begin{abstract}
:
Introduction: The greatest preventive challenge in dentistry is the control of dental biofilm and consequently avoiding dental caries and gingival inflammation. As an adjunct to the mechanical oral hygiene measures, chemical antimicrobial agents seem to offer great benefits in the control of plaque formation and gingivitis, especially in high risk patients wearing orthodontic appliances.

Objective: The aim of the study was to evaluate the effect of Triclosan $(0.3 \%)$ Colgate Total ${ }^{\circledR}$ on gingivitis and plaque formation in patients wearing fixed orthodontic appliances.

Materials and methods: Fifty children wearing fixed orthodontic appliances with an age range of 9 to 13 years were randomly assigned into 2 groups (test and control). The test group received the Colgate Total ${ }^{\circledR}$ toothpaste containing $0.32 \%$ sodium fluoride and $0.3 \%$ Triclosan. The control group received maxfresh ${ }^{\circledR}$ toothpaste containing $0.22 \%$ sodium fluoride. All patients were examined clinically to assess their gingival condition using the Plaque index (PI), Gingival Index (GI), Sulcular Bleeding Index (SBI) at follow up periods of 1, 2 and 3 months. Each group shifted to use the alternative agent after a washout period of 10 days to prevent the carryover effect of Triclosan.

Results: Showed that the Triclosan toothpaste users experienced significant reduction in plaque accumulation and gingivitis compared to the fluoride toothpaste users in the first and second follow up periods. The results also showed significant difference compared to the baseline.

Conclusion: Triclosan toothpaste proved to have marked antiplaque and antigingivitis effects. Triclosan toothpaste proved to counteract the aggravated gingival effects that can be introduced by the fixed orthodontic appliances in children at the age of puberty.
\end{abstract}

Keywords: Triclosan, toothpaste, plaque, gingivitis, children, orthodontic appliances

1- Instructor, Department of Pediatric Dentistry, Faculty of Dentistry, Pharos University in Alexandria.

2 - Professor, Department of Pediatric Dentistry, Faculty of Dentistry, Alexandria University.

\section{INTRODUCTION}

One of the main concerns of dentistry nowadays is the improvement of the individual's facial appearance, since it is considered one of the major factors in determining one's integration into society (1). Orthodontic treatment is a crucial part of the complete dental rehabilitation, which includes improvements in dental health, function, appearance and eventually self-esteem. Although this kind of treatment in turn leaves countless positive effects on the patient's personality and appearance, it can cause harm to the patient's gingival conditions after the placement of a fixed appliance (2). Fortunately, gingival inflammation is usually temporary and does not lead to attachment loss (2-4). In addition, gingival hyperplasia is usually noticed around orthodontic bands, leading to pseudo-pocketing giving a false picture of a periodontal disease. The condition usually resolves within weeks after finishing the treatment provided that proper oral hygiene practices are followed throughout the orthodontic treatment period, otherwise the condition worsens (5). Bleeding usually is experienced due to the micro-ulcerations that occur in the epithelium that lines the gingival sulcus (6).

Orthodontic appliances, especially fixed bonded appliances, can complicate the oral hygiene maintenance process by introducing large numbers of plaque retentive irregular surfaces in the oral environment $(7,8)$. An increased gingival irritation can be attributed to the mechanical irritation caused by the subgingival placement of the orthodontic bands, which may also result in the translocation of bacterial plaque to the subgingival region during the physiological tooth movement (9). Young patients approaching the age of puberty are occasionally less interested in oral hygiene which in the presence of fixed orthodontic appliances becomes a more difficult routine (10). Adequate mouth hygiene and cleanliness of the teeth are related to the frequency of brushing and the adequate removal of bacterial plaque from the tooth surface (11). Despite of the documented relationship between poor oral hygiene and gingival inflammation, it is still advocated that self-performed plaque control measures are not entirely efficient to control gingival inflammation (12). The addition of antimicrobial agents to conventional toothpastes has the ultimate goal of increasing the effect of control or elimination of microorganisms involved in many oral microbial infections in the human mouth to control gingival diseases (13).

Triclosan is a low-toxicity, non-ionic, chlorinated bisphenol that is compatible with toothpaste components, such as fluoride and surfactants. Triclosan has been reported to promote inhibition of cyclooxygenase/lipoxygenase pathways and exhibits anti-inflammatory effects $(14,15)$. Considering the information available on the material, Triclosan has been proven to be safe and effective as a broad-spectrum antibacterial agent. It has also been proven to be compatible with two of the most used salts in dentistry, sodium fluoride and sodium monofluorophosphate (16).

Colgate Total, which contains Triclosan, stands as the only toothpaste approved by the US Food and Drug Administration as well as the American Dental Association (ADA) to fight plaque and gingivitis, therefore it is mostly recommended by dentists and hygienists to be used in the US (17). Since too many commercial oral cleansers with 
different antibacterial agents are available in the market, this study aimed to test the hypothesis that combining the benefit of mechanical plaque removal with the potential antibacterial effect of the $0.3 \%$ Triclosan toothpaste would be of superior benefit compared to fluoride toothpaste when used by children undergoing orthodontic treatment, and whom are considered at high risk to gingival disease.

\section{MATERIALS AND METHODS}

This study was planned to be a randomized clinical trial based on a crossover design to evaluate the effect of Triclosan toothpaste compared to conventional fluoride toothpaste. The required sample size was calculated using Epi-info software and accordingly an estimated sample of 25 children per group was considered adequate. A power of $80 \%$ was used to detect a clinically meaningful reduction in plaque index from baseline to 3 months among the study groups (18) with precision of $5 \%, \alpha=0.05$, effect size $=0.85$.

Fifty children with an age range of 9-13 years were selected from the Pediatric Dentistry Department as well as the Orthodontic Department, Faculty of Dentistry, Alexandria University. Exclusion criteria were:

1. Children wearing removable orthodontic appliances.

2. Medically compromised or intellectually disabled patients.

3. Children with special health care needs affecting their motor function.

4. Children with severe gingivitis more than grade 2 (gingival index according to Loe and Silness) (19).

The sample was randomly divided into 2 groups using the Fish Bowl technique to achieve random allocation to the study groups.

Group I: Colgate Total ${ }^{\circledR}$ toothpaste containing the $0.32 \%$ sodium fluoride plus the active ingredient $0.3 \%$ Triclosan (test group). *

Group II: Colgate Maxfresh ${ }^{\circledR}$ toothpaste containing $0.22 \%$ sodium fluoride (control group) $* *$

Each child was informed to brush twice daily with the assigned toothpaste and provided with a follow up chart each visit where the dentist and the parent assessed the compliance of the child. The children colored in the follow up chart each time they brushed their teeth.

After a washout period of 10 days (20), the participants in each group were reallocated to the counterpart group and used the alternative agent (crossover procedure). Each candidate in each group was supplied with an orthodontic toothbrush recommended by the orthodontist at the beginning of the study. After the washout period and the crossover, the patients were supplied with another toothbrush to be used in the second 3 month period.

In order to assess the gingival conditions, the following indices were used:

Plaque index (PI) (21), Gingival Index (GI) $(22,6)$, and Sulcular Bleeding Index (SBI) (6).

Baseline assessment of plaque and gingivitis was carried out using the previously mentioned indices. Each participant was reevaluated for plaque, gingivitis and gingival bleeding levels at 1, 2 and 3 month intervals. Based on the half-life period of ingested Triclosan in the body (23), a washout period of 10 days was given to each group during which children were instructed to use the control toothpaste before they shifted to the alternative one. Reevaluation of the final outcome was carried out using the same indices at follow up intervals of 1,2 and 3 months.

The present study was performed after receiving the approval of the Research Ethics Committee in the Faculty of Dentistry, Alexandria University. Parents of the selected children signed an informed consent after explaining the nature of the study, that their children will receive 2 different toothpastes throughout the follow up periods (1 every 3 months) and how the test material can offer better gingival health.

\section{Statistical analysis:}

Data were fed to the computer and analyzed using IBM SPSS software package version 20.0. Qualitative data were described using number and percent. Quantitative data were described using range (minimum and maximum) mean, standard deviation and median. Comparisons between different groups regarding categorical variables were tested using Chi-square test. The distributions of quantitative variables were tested for normality using KolmogorovSmirnov test, Shapiro-Wilk test and D'Agstino test. If data revealed normal data distribution, parametric tests were applied. If data were abnormally distributed, non-parametric tests were used. Comparisons between the two studied groups were done using Mann Whitney test while comparisons between the different periods were done using Friedman test and pair wise comparison was assessed using Wilcoxon signed ranks test. Significance of the obtained results was judged at the $5 \%$ level.

\section{RESULTS}

Children who participated in the study had an age range of $9-13$ years with a mean age of $11.58 \pm 1.36$ years. Out of the total sample, $37.8 \%$ were males and $62.2 \%$ were females. Following randomization, there was no statistically significant difference between the two groups regarding age and gender, $(\mathrm{P}=0.254)$ and $(\mathrm{P}=0.918)$ respectively.

In group 1, the comparisons in the first follow up period regarding the Plaque index (PI) revealed statistically significant difference between the mean values of baseline, first, second and third month using the Friedman test $(\mathrm{P}=0.017)$. When each of the first, second and the third month mean values were compared to the baseline, statistically significant differences were also revealed $[(\mathrm{P}=0.003),(\mathrm{P}=0.012)$ and $(\mathrm{P}=0.002)$ respectively $]$. There were reductions in the percentage of change from the baseline value by $40.7 \%$ in the first month, $33.3 \%$ in the second month and $37.8 \%$ in the third month indicating a marked decrease in the plaque formation in the first month. The reduction fluctuated during the following months.

In group 2, comparison of the baseline, first, second and third month mean values using the Friedman test revealed no statistically significant difference $(\mathrm{P}=0.149)$. Comparing the mean values of the first, second and third month with the baseline value revealed statistically significant difference only in the third month $[(\mathrm{P}=0.419),(\mathrm{P}=0.120)$ and $(\mathrm{P}=0.048)$ 
respectively]. The decrease in the percentage of change was only $8.8 \%$ in the first month, $14.7 \%$ in the second month and $22.1 \%$ in the third month. The results indicated gradual decrease in the amount of plaque formation in the first, second and third months respectively.

When the 2 groups were compared in the first, second and third months, only statistically significant difference was seen in the first month $(\mathrm{P}=0.016)$, whereas no statistically significant differences between groups were evident in the second and third months $[(\mathrm{P}=0.169)$ and $(\mathrm{P}=0.232)$ respectively] as shown in figure 1 .

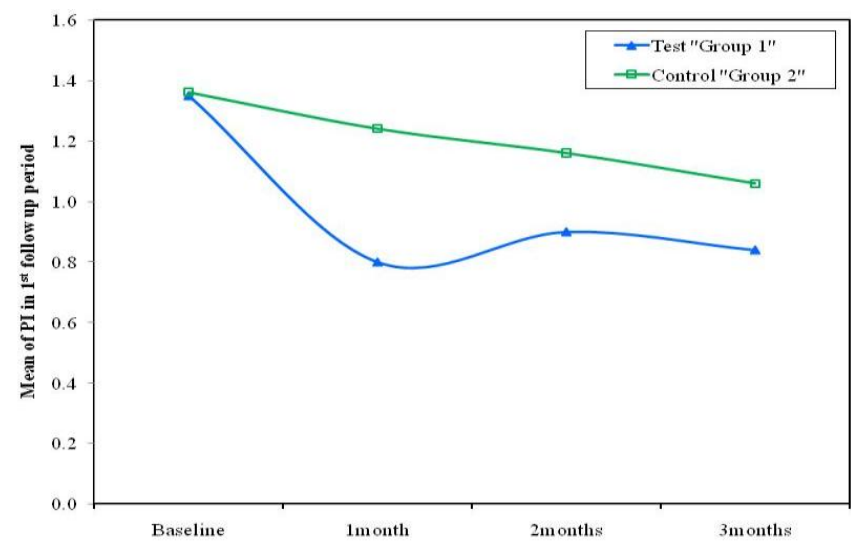

Fig. 1: Comparison between the test and control groups in the first follow up period regarding Plaque Index (PI)

In group 1, the comparisons in the first follow up period regarding the Gingival Index (GI) revealed a statistically significant difference between the baseline, first, second and third month mean values using the Friedman test $(\mathrm{P}<0.001)$. When each of the first, second and the third month mean values were compared to the baseline, statistically significant differences were revealed $[(\mathrm{P}=0.001),(\mathrm{P}=0.002)$ and $(\mathrm{P}=0.003)$ respectively]. There was a decrease in the percentage of change from baseline value by $31.7 \%$ in the first month, $26.8 \%$ in the second month and $34.1 \%$ in the third month. This indicated maximum improvement in the gingival condition in the third month and a slight drop in the second one.

In group 2, comparison of the baseline, first, second and third month mean values using the Friedman test revealed no statistically significant difference $(\mathrm{P}=0.286)$. Comparing each of the first, second and third month mean values to the baseline value, no statistically significant differences were revealed [ $(\mathrm{P}=0.739),(\mathrm{P}=0.285)$ and $(\mathrm{P}=0.405)$ respectively]. The first month showed an increase in the percentage of change with a value of $2.3 \%$ indicating a worsened gingival condition, whereas the second and third months showed slight reduction in the percentage of change with values of $9.3 \%$ and $7.0 \%$ respectively indicating slight improvement in the gingival condition.

When comparing both groups in the first, second and third months, statistically significant differences were found $[(\mathrm{P}<0.001),(\mathrm{P}=0.029)$ and $(\mathrm{P}=0.004)$ respectively] as shown in figure 2.

In group 1, the comparisons in the first follow up period regarding the Sulcular Bleeding Index (SBI) revealed a statistically significant difference between the baseline, first, second and third month mean values using the Friedman test $(\mathrm{P}<0.001)$. When each of the first, second and the third month mean values were compared to the baseline, statistically significant differences were revealed $[(\mathrm{P}=0.003),(\mathrm{P}=0.003)$ and $(\mathrm{P}=0.001)$ respectively]. There was a decrease in the percentage of change with values of $50.0 \%$ in the first month, $47.4 \%$ in the second month and $68.4 \%$ in the third month indicating improvement in the gingival bleeding condition.

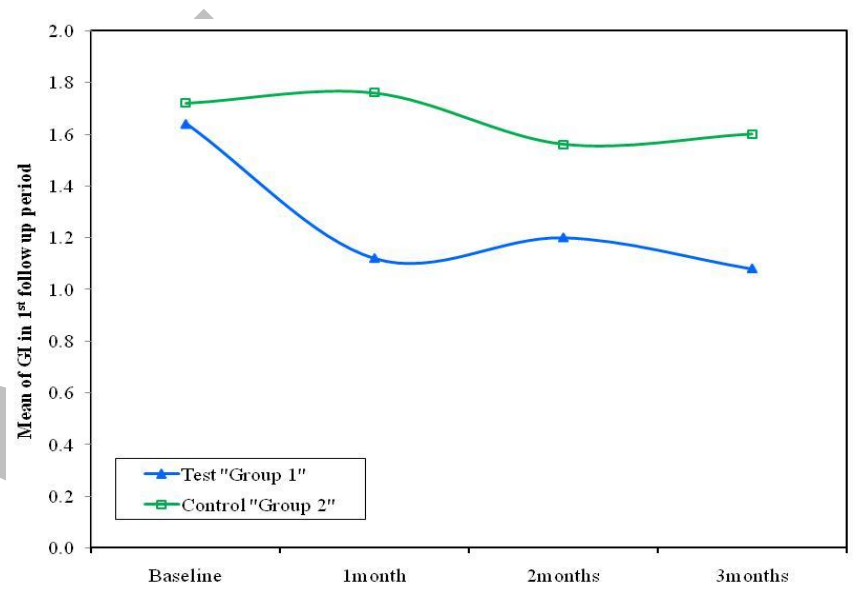

Fig. 2: Comparison between the test and control groups in the first follow up period regarding Gingival Index (GI)

In group 2, comparing the baseline, first, second and third month mean values using the Friedman test revealed a statistically significant difference $(\mathrm{P}=0.001)$. When each of the first, second and the third month mean values were compared to the baseline, statistically significant differences were revealed $[(\mathrm{P}=0.084), \quad(\mathrm{P}=0.015)$ and $\quad(\mathrm{P}=0.004)$ respectively]. There was a decrease in the percentage of change with values of $22.2 \%$ in the first month, $31.1 \%$ in the second month and $56.7 \%$ in the third month which also indicates improvement in the bleeding condition of the gingiva throughout the 3 months.

Comparisons of both groups in the first, second and third months, revealed statistically significant differences $(\mathrm{P}=0.006),(\mathrm{P}=0.008)$ and $(\mathrm{P}=0.050)$ respectively as shown in figure 3 .

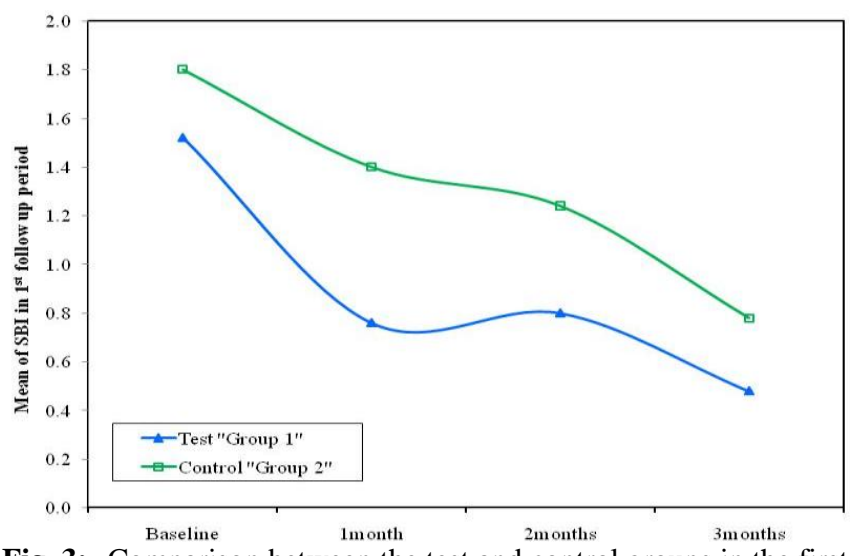

Fig. 3: Comparison between the test and control groups in the first follow up period regarding Sulcular Bleeding Index (SBI) 
In the second follow up period, the test group comparisons regarding the PI revealed a statistically significant difference between the baseline, first, second and third month mean values using the Friedman test $(\mathrm{P}<0.001)$. When each of the first, second and the third month mean values were compared to the mean value after the washout period, statistically significant differences were revealed $[(\mathrm{P}<0.001)$ at each month]. There was a decrease in the percentage of change with values of $45.9 \%$ in the first month, $43.4 \%$ in the second month and $63.1 \%$ in the third month respectively indicating a decrease in plaque formation during the follow up period with maximum effect in the third month.

In the control group, comparison of the baseline, first, second and third month mean values using the Friedman test revealed no statistically significant difference $(\mathrm{P}=0.109)$. When each of the first, second and the third month mean values were compared to the group mean value after the washout period, statistically significant difference was evident in the second month $[(\mathrm{P}=0.109),(\mathrm{P}=0.004)$ and $(\mathrm{P}=0.115)$ in the first, second and third months respectively]. Also there was an increase in the percentage of change with the values of $19.3 \%$ in the first month, $27.7 \%$ in the second month and $18.1 \%$ in the third month respectively. This indicated increase in plaque formation with maximum increase in the second month.

Comparisons of both groups in the second follow up period regarding the PI revealed statistically significant difference $[(\mathrm{P}=0.006),(\mathrm{P}<0.001)$ and $(\mathrm{P}<0.001)$ in the first, second and third month respectively] as shown in figure 4.

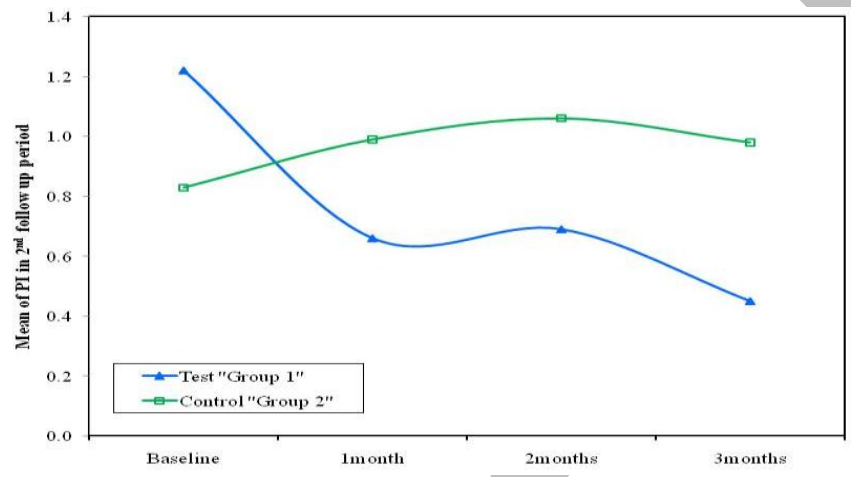

Fig. 4: Comparison between the test and control groups in the second follow up period regarding Plaque Index (PI)

In the second follow up period, the test group comparisons between the baseline, first, second and third month mean values revealed a statistically significant difference using the Friedman test $(\mathrm{P}<0.001)$. When each of the first, second and the third month mean values were compared to the group mean value after the washout period, statistically significant differences were revealed [( $\mathrm{P}=0.004),(\mathrm{P}<0.001)$ and $(\mathrm{P}<0.001)$ respectively]. There was a decrease in the percentage of change with the values of $23.8 \%$ in the first month, $38.1 \%$ in the second month and $38.1 \%$ in the third month respectively indicating an improvement in the gingival condition.

In the control group, comparing the baseline, first, second and third month mean values using the Friedman test revealed a statistically significant difference $(\mathrm{P}<0.001)$.
When each of the first, second and the third month mean values were compared to the group mean value after the washout period, statistically significant differences were revealed $[(\mathrm{P}<0.001)$ in each month respectively]. There was an increase in the percentage of change with the values of $77.3 \%$ in the first month, $77.3 \%$ in the second month and $68.2 \%$ in the third month respectively. This indicated deterioration of the gingival condition in the first and second month followed by slight improvement in the third month.

Comparisons of groups regarding the GI revealed statistically significant differences in the second and third months only $[(\mathrm{P}=0.065),(\mathrm{P}=0.001)$ and $(\mathrm{P}=0.004)$ in the first, second and third months respectively] as shown in figure 5 .

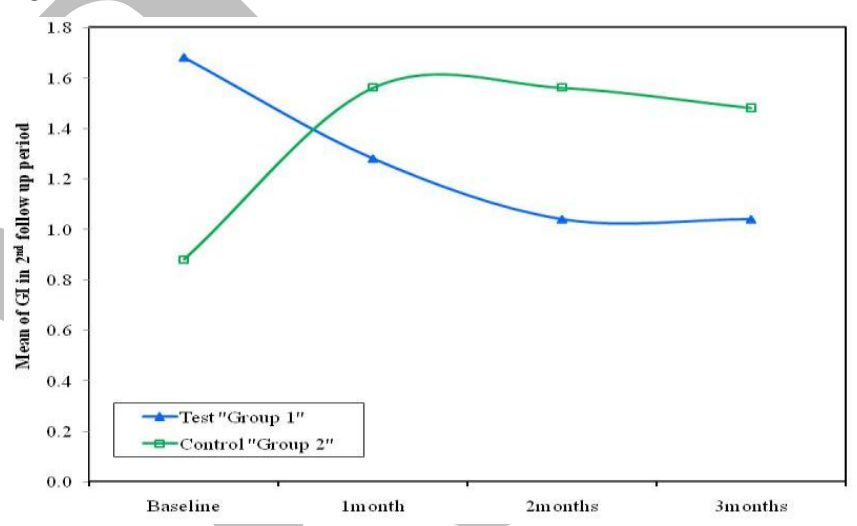

Fig. 5: Comparison between the test and control groups in the second follow up period regarding Gingival Index (GI)

In the second follow up period, the test group comparisons regarding the SBI revealed a statistically significant difference between the baseline, first, second and third month mean values using the Friedman test $(\mathrm{P}<0.001)$. When each of the first, second and the third month mean values were compared to the baseline value after the washout period, statistically significant differences were revealed $[(\mathrm{P}<0.001)$ in each month]. There was a decrease in the percentage of change with values of $67.5 \%$ in the first month, $80.0 \%$ in the second month and $85.0 \%$ in the third month respectively indicating marked improvement in the bleeding condition of the gingiva.

In the control group, comparing the baseline, first, second and third month mean values using the Friedman test revealed no statistically significant difference $(\mathrm{P}=0.137)$. When each of the first, second and the third month mean values were compared to the baseline value after the washout period, no statistically significant differences were seen $[(\mathrm{P}=0.071),(\mathrm{P}=0.088)$ and $(\mathrm{P}=0.513)$ in the first, second and third months respectively]. There was an increase in the percentage of change with the values of $47.4 \%$ in the first month, $42.1 \%$ in the second month and $15.8 \%$ in the third month respectively indicating deterioration in the bleeding condition of the gingiva except for the third month which showed slight improvement.

Comparisons of groups regarding the SBI revealed statistically significant differences in the first, second and third months $[(\mathrm{P}=0.007), \quad(\mathrm{P}<0.001)$ and $\quad(\mathrm{P}=0.003)$ respectively] as shown in figure 6 . 
Table 1 shows comparison between the third month of the first and second follow up period in the same group. In group 1, children used the Triclosan toothpaste in the first follow up period and after the crossover they shifted to use

Table (1): Comparison between the 3rd months of the 1st and 2nd follow up periods in the same group.

\begin{tabular}{|c|c|c|c|c|c|}
\hline & & \multicolumn{2}{|c|}{$1^{\text {st }}$ period } & \multicolumn{2}{|c|}{$2^{\text {nd }}$ period } \\
\hline & & Baseline & 3months & Baseline & 3months \\
\hline \multirow{8}{*}{$\Xi$} & $\begin{array}{l}\text { Group 1 } \\
\text { Min. - Max. } \\
\text { Mean } \pm \text { SD } \\
\text { Median } \\
\end{array}$ & $\begin{array}{c}0.30-2.0 \\
1.35 \pm 0.54 \\
1.0\end{array}$ & $\begin{array}{c}0.0-2.0 \\
0.84 \pm 0.62 \\
1.0\end{array}$ & $\begin{array}{c}0.50-1.30 \\
0.83 \pm 0.25 \\
0.80\end{array}$ & $\begin{array}{c}0.0-1.70 \\
0.98 \pm 0.40 \\
1.0 \\
\end{array}$ \\
\hline & $\begin{array}{l}\text { \% of } \\
\text { Chg.(1) }\end{array}$ & & $\downarrow 37.8$ & & $\uparrow 18.1$ \\
\hline & & & & & 0.268 \\
\hline & $\begin{array}{l}\text { \% of } \\
\text { Chg.(2) } \\
\end{array}$ & & & & $\uparrow 16.7$ \\
\hline & $\begin{array}{l}\text { Group 2 } \\
\text { Min. - Max. } \\
\text { Mean } \pm \text { SD } \\
\text { Median } \\
\end{array}$ & $\begin{array}{c}0.50-2.0 \\
1.36 \pm 0.45 \\
1.30\end{array}$ & $\begin{array}{c}0.30-2.50 \\
1.06 \pm 0.54 \\
1.0 \\
\end{array}$ & $\begin{array}{c}0.50-2.0 \\
1.22 \pm 0.40 \\
1.0\end{array}$ & $\begin{array}{c}0.0-1.0 \\
0.45 \pm 0.39 \\
0.50\end{array}$ \\
\hline & $\begin{array}{l}\text { \% of } \\
\text { Chg.(1) }\end{array}$ & & $\downarrow 22.1$ & & $\downarrow 63.1$ \\
\hline & & & & & $<0.001^{*}$ \\
\hline & $\begin{array}{l}\text { \% of } \\
\text { Chg.(2) } \\
\end{array}$ & & & & $\downarrow 57.5$ \\
\hline \multirow{8}{*}{ כ } & $\begin{array}{l}\text { Group 1 } \\
\text { Min. - Max. } \\
\text { Mean } \pm \text { SD } \\
\text { Median } \\
\end{array}$ & $\begin{array}{c}1.0-2.0 \\
1.64 \pm 0.49 \\
2.0\end{array}$ & $\begin{array}{c}0.0-2.0 \\
1.08 \pm 0.64 \\
1.0 \\
\end{array}$ & $\begin{array}{c}0.0-1.0 \\
0.88 \pm 0.33 \\
1.0\end{array}$ & $\begin{array}{c}0.0-2.0 \\
1.48 \pm 0.59 \\
2.0\end{array}$ \\
\hline & $\begin{array}{l}\text { \% of } \\
\text { Chg.(1) }\end{array}$ & & $\downarrow 34.1$ & & $\uparrow 68.2$ \\
\hline & $\mathbf{p}$ & & & & $0.008^{*}$ \\
\hline & $\begin{array}{l}\text { \% of } \\
\text { Chg.(2) }\end{array}$ & & & & $\uparrow 37.0$ \\
\hline & $\begin{array}{l}\text { Group 2 } \\
\text { Min. - Max. } \\
\text { Mean } \pm \text { SD } \\
\text { Median } \\
\end{array}$ & $\begin{array}{c}1.0-2.0 \\
1.72 \pm 0.46 \\
2.0 \\
\end{array}$ & $\begin{array}{c}1.0-2.0 \\
1.60 \pm 0.50 \\
2.0 \\
\end{array}$ & $\begin{array}{c}0.0-2.0 \\
1.68 \pm 0.48 \\
2.0\end{array}$ & $\begin{array}{c}0.0-2.0 \\
1.04 \pm 0.45 \\
1.0 \\
\end{array}$ \\
\hline & $\begin{array}{l}\text { \% of } \\
\text { Chg.(1) }\end{array}$ & & $\downarrow 7.0$ & & $\downarrow 38.1$ \\
\hline & p & & & & $<0.001^{*}$ \\
\hline & $\begin{array}{l}\% \text { of } \\
\text { Chg.(2) }\end{array}$ & & & & $\downarrow 35.0$ \\
\hline \multirow{10}{*}{ कै } & $\begin{array}{l}\text { Group 1 } \\
\text { Min. - Max. } \\
\text { Mean } \pm \text { SD } \\
\text { Median } \\
\end{array}$ & $\begin{array}{c}0.0-3.0 \\
1.52 \pm 0.77 \\
2.0 \\
\end{array}$ & $\begin{array}{c}0.0-2.0 \\
0.48 \pm 0.71 \\
0.0\end{array}$ & $\begin{array}{c}0.0-1.0 \\
0.76 \pm 0.44 \\
1.0\end{array}$ & $\begin{array}{c}0.0-2.0 \\
0.88 \pm 0.83 \\
1.0 \\
\end{array}$ \\
\hline & $\begin{array}{l}\text { \% of } \\
\text { Chg.(1) }\end{array}$ & & $\downarrow 68.4$ & & $\uparrow 15.8$ \\
\hline & p & & & & $0.032^{*}$ \\
\hline & $\begin{array}{ll}\% \text { of } \\
\text { Chg.(2) } \\
\end{array}$ & & & & $\uparrow 83.3$ \\
\hline & Group 2 & & & & \\
\hline & $\begin{array}{l}\text { Min. - Max. } \\
\text { Mean } \pm \text { SD }\end{array}$ & $\begin{array}{c}0.0-3.0 \\
1.80 \pm 0.87\end{array}$ & $\begin{array}{c}0.0-2.0 \\
0.78 \pm 0.82\end{array}$ & $\begin{array}{c}0.0-3.0 \\
1.60 \pm 0.76\end{array}$ & $\begin{array}{c}0.0-1.0 \\
0.24 \pm 0.44\end{array}$ \\
\hline & Median & 2.0 & 1.0 & 2.0 & 0.0 \\
\hline & $\begin{array}{l}\% \text { of } \\
\text { Chg.(1) }\end{array}$ & & $\downarrow 56.7$ & & $\downarrow 85.0$ \\
\hline & $\mathbf{p}$ & & & & $<0.001^{*}$ \\
\hline & $\begin{array}{l}\text { \% of } \\
\text { Chg.(2) }\end{array}$ & & & & $\downarrow 69.2$ \\
\hline
\end{tabular}

$\%$ of Chg (1): \% of change from base line to 3 months of each follow up period in the same group

$\%$ of Chg (1): \% of change from 3 months of the 1st follow up period to the 3 months of the 2 nd follow up period in the same group

$\mathrm{p}$ : $\mathrm{p}$ value for Wilcoxon signed ranks test for comparing between 3 months of the 1 st follow up period and the 3 months of the 2 nd follow up period in the same group

*: Statistically significant at $\mathrm{p} \leq 0.05$

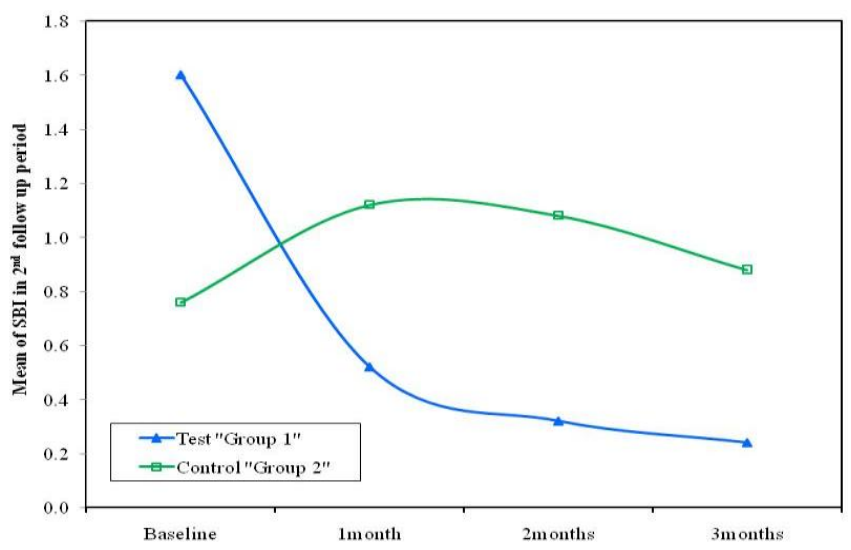

Fig. 6: Comparison between the test and control groups in the second follow up period regarding Sulcular Bleeding Index (SBI)

the control toothpaste. Results showed significant differences regarding only the GI and SBI $[(\mathrm{P}=0.268)$, $(\mathrm{P}=0.008)$ and $\mathrm{P}=(0.032)$ for the $\mathrm{PI}, \mathrm{GI}$ and $\mathrm{SBI}$ respectively]. The percentage of change from the third month of the first follow up period to the third month of the second one increased by $16.7 \%, 37.0 \%$ and $83.3 \%$ for the PI, GI and SBI respectively.

In group 2, children used the control toothpaste in the first follow up period and after the crossover they shifted to the Triclosan toothpaste. Results showed significant differences $[(\mathrm{P}=0.001)$ in the PI, GI and SBI respectively]. The percentage of change from the third month of the first follow up period to the third month of the second one decreased by $57.5 \%, 35.0 \%$ and $69.2 \%$ for the PI, GI and SBI respectively.

\section{DISCUSSION}

Since orthodontic treatment has been increasingly performed due to the social demands, the present study was planned to explore a new convenient method to prevent this potential problem, which is gingivitis during and after orthodontic treatment. This study aimed at evaluating the effect of $0.3 \%$ Triclosan toothpaste on gingivitis and plaque formation which appear after fixed orthodontic appliance construction.

In the current study, a general trend of constant improvement in the Triclosan toothpaste users with statistically significant differences from the baseline throughout the follow up periods regarding the PI, GI and SBI. Similarly, the control group showed slight improvement in the plaque accumulation and gingivitis that did not reach significant levels. The improvement in the SBI was significant. This may be due to the fact that mechanical plaque removal also contributed to the better gingival condition.

Regarding the PI, improvement was seen among the test toothpaste users in both the first and second follow up periods. However, some fluctuations were evident in both periods. This may be attributed to the fact that participants experienced a sense of habituation and loss of interest in the strict oral hygiene regimen. Participants may have thought that they achieved their goal in maintaining good oral 
hygiene after the marked improvement and appraisal by the examiner. After reinforcing oral hygiene instructions, participants were remotivated and showed improved compliance throughout the following months through assessment of the follow up chart.

Similar fluctuations in the results were shown regarding the GI and SBI during the first follow up period. In the second follow up period, the GI and SBI showed a constant improvement in their gingivitis and plaque levels. This may be attributed to the fact that shifting to the test toothpaste and exposing them to the chemotherapeutic effect of Triclosan caused pronounced improvement in their oral condition. They probably would have benefited from their experience in the first follow up period during which they were under strict oral hygiene practices.

Regarding the control toothpaste, the mean values of the PI, GI and SBI showed slight improvement in the plaque formation and gingival conditions in the first follow up period. The results showed slight fluctuation in the mean values of the GI. The mean values of the SBI showed marked improvement than PI and GI in the first follow up period. This indicated that although no therapeutic agent exits, mechanical plaque removal (brushing twice daily) under strict supervision improved the gingival condition especially bleeding gums. Brushing twice daily is considered the most common method of plaque control and has been recommended by the American Dental Association as a regimen for good oral hygiene (24).

In the second follow up period, the results showed increase in the mean values of the PI, GI and SBI. The increase showed nearly the same pattern in the 3 indices; a marked increase in the first month followed by minimum improvement in the second and third months. This indicated deterioration in the oral hygiene and the gingival conditions following shifting from the test to the control toothpaste. Although the conditions improved in the third month, the differences between the test and control groups were statistically significant. Moreover, when comparing the third months of the first and the second follow up periods the Triclosan showed greater improvement in the oral hygiene, gingivitis and gingival bleeding conditions.

The present results were confirmed in many literature reviews. Reviews done by Davis et al in 2004 (25), Gunsolley in 2006 (26), and Blinkhorn et al in 2009 (27) concluded that Triclosan toothpaste reduces formation of supragingival plaque and incidence of gingivitis when compared to conventional fluoride toothpaste.

Similarly, the same results were proven by DeVizio in 2008 (28) and by Singh et al in 2010 (29) in their six week clinical investigation. Singh et al concluded that the toothpaste containing $0.3 \%$ Triclosan, $2.0 \%$ PVM/MA copolymer and $0.243 \%$ sodium fluoride is efficacious in reducing gingivitis and supragingival plaque. They also provided evidence in their study that the this toothpaste provides a greater level of antiplaque and antigingivitis effect than does the toothpaste containing $0.454 \%$ stannous fluoride, sodium hexametaphosphate and zinc lactate.

However, the study of He et al in 2013 (30) showed that not all patients display the same response to the toothpaste.
In their study, they proved that patients already using $0.3 \%$ Triclosan toothpaste with residual gingivitis showed reduction in the gingival inflammation and bleeding when shifting to the $0.454 \%$ stannous fluoride toothpaste compared to those who continued using the $0.3 \%$ Triclosan toothpaste.

On the other hand, Bhavesh et al in 2011 (34) found that both Triclosan and Chlorhexidine equally inhibited the colonization of Streptococcus mutans on the orthodontic components and thus the same incidence of plaque formation and gingivitis.

Although Chlorhexidine has significant effect on plaque formation and gingivitis, the use of this therapeutic agent is not advocated for long periods. The use of Triclosan seems to be more useful and safer in patients who are exposed to the risk of gingivitis for the periods needed during their orthodontic treatment.

\section{CONCLUSIONS}

1. Triclosan toothpaste proved to have marked antiplaque and antigingivitis effects.

2. Triclosan toothpaste proved to counteract the gingivitis aggravated by the fixed orthodontic appliances in children at the age of puberty.

\section{CONFLICT OF INTEREST}

The authors declare that they have no conflicts of interest.

\section{REFERENCES}

1. Moynihan P, Petersen P. Diet, Nutrition and the prevention of dental diseases. Public Health Nutr. 2004; 7(1A): $201-26$.

2. Ellis P, Benson P. Potential hazards of orthodontic treatment- what your patient sould know. Dent Update. 2002; 29: 492-6.

3. Sadowsky C, BeGole E. Long term effects of orthodontic treatment on periodontal health. Am J Orthod. 1981; 80: 156-72.

4. Polson A, Subtelny J, Mertner S. Long term periodontal status after orthodontic treatment. Am J Orthod Dentofac Orthop. 1988; 93: 51-8.

5. Zachrisson B. Cause and prevention of injuries to teeth and supporting structures during orthodontic treatment. Am J Orthod. 1976; 69: 285-300.

6. Rebelo M, DeQueiroz A. Gingival Indices: State of Art. In: Gingival Diseases - Their Aetiology, Prevention and Treatment. InTech, 2011. 42-54.

7. Eliades T, Eliades G, Brantley W. Microbial attachment on orthodontic appliances. Wettability and early pellicle formation on bracket materials. Am $\mathrm{J}$ Orthod Dentofacial Orthop. 1995; 108: 351-60.

8. Lee S, Lee S, Jim B, Ahn S. Surface characteristics of orthodontic materials and their effect on adhesion of Mutans Streptococci. Angel Orthod. 2009; 79: 353-60.

9. Ericsson I, Thilande B, Lindhe J. Periodontal conditions after orthodontic movements in dog. Angle Orthodont. 1978; 48: 210-18.

10. Jeffcoat M. Pits and pitfalls of clinical trial designs. J Periodontol 2000. 1992; 63: 1045-51. 
11. McDonald R, Avery D, Dean J. Dentistry for child and adolescent. 9th ed.: Mosby; 2011.

12. O'Mullane D. New agents in the control of plaque and gingivitis reaction paper. J Dent Res. 1992; 71: 1455-6.

13. Saravia M, Nelson-Filho P, Silva R, De Rossi A, Faria G, Silva L. Recovery of Mutans Streptococci on MSB, SB-20 and SB-20M agar media. Arch Oral Biol. 2013; 58: 311-6.

14. Davies R. Toothpaste in the control of plaque/gingivitis and periodontitis. periodontol 2000. 2008; 48: 23-30.

15. Davies R, Scully C, Preston A. Dentifrices-an update. Med Oral Patol Oral Cir Bucal. 2010; 15: 976-82.

16. European Commission. Directorate General for Health $\&$ Consumers. Opinion on triclosan, addendum to the SCCP Opinion on Triclosan (SCCP/1192/08). 2009 January. Brussels: European Commission.

17. Ciancio S, Panagakos F. Superior Management of Plaque and Gingivitis Through the Use of a Triclosan/Copolymer Dentifrice. J Clin Dent. 2010; 21: 93-5.

18. Boneta A, Aguilar M, Romeu F, Stewart B, DeVizio W, Proskin H. Comparative investigation of the efficacy of Triclosan/Copolymer/Sodium Fluoride and Stannous Fluoride/Sodium Hexametaphosphate/Zinc Lactate dentifrices for the control of the established supragingival plaque and gingivitis in a six month clinical study. J Clin Dent 2010; 21: 117-23.

19. Willershausen B, Kasaj A, Sculean A, Wehrbein H. Influence of herbal mouthwash on inflammatory changes of the gingiva in patients with fixed orthodontic appliances. Perio. 2004; 1(3): 255-62.

20. Calafat A, Xiaoyun Y, Wong L, Reidy J, Needham L. Urinary concentrations of Triclosan in the U.S population : 2003-2004. Environ Health Prospect. 2008; 116(3): 303-7.

21. Darby M, Walsh M. Dental Hygiene Theory and Practice. St. Louis, Mo.: Saunders/Elsevier, 2010. 1-4.

22. Newman M, Takei H, Carranza F. Carranza's Clinical Periodontology. In: WB Saunders. Philadelphia; 2006. 141-7.

23. ADA: American Dental Association - Cleaning Your Teeth \& Gums." ADA: American Dental Association Home. N.p., n.d. Web. 5 Aug. 2015.

24. Davies R, Ellwood R, Davies G. The effectiveness of a toothpaste containing triclosan and polyvinylmethyl ether/maleic acid copolymer in improving plaque control and gingival health. A systematic review. J Clin Periodontol. 2004; 31: 1029-33.

25. Gunsolley J. A meta-analysis of six-month studies of antiplaque and antigingivitis agents. J Am Dent Assoc. 2006; 137: 1649-57.

26. Blinkhhorn A, Bartold P, Cullinan M, Madden T, Marshall R, Raphael S, et al. Is there a role for Triclosaan/Copolymer toothpaste in management of periodontal disease. Br Dent J. 2009; 207: 117-25.

27. DeVizio W. The efficacy of a new dentifrice with caries, plaque, gingivitis, calculus, tooth whitening, and malodor benefits. J Clin Dent. 2008; 19: 79-80.
28. Singh S, Chakins $\mathrm{P}$, De vizio W, Petrone M, Panagakos F, Proskin H. A clinical investigation of the efficacy of 3 commercially available dentifrices for controlling established gingivitis and supragingival plaque. J Clin Dent. 2010; 21: 105-10.

29. He T, Barke L, Biesbrock A, Miner M, Amini P, Goyal $\mathrm{R}$, et al. Evaluation of anti-gingivitis benefits of Stannous Fluoride dentifrice among Triclosan dentifrice users. Am J Dent 2013; 26: 175-9.

30. Kthari B, Bhad W. Antimicrobial efficacy of Chlorhexidine and Triclosan on the Orthodontic appliance components: An in-vivo comparative microbial cultur study. ADR. 2011; 1(1): 1-11. 